International Research Journal of Engineering, IT \& Scientific Research
Available online at https://sloap.org/journals/index.php/irjeis/
Vol. 6 No. 2, March 2020, pages: 1 -6
ISSN: 2454-2261
https://doi.org/10.21744/irjeis.v6n2.856

\title{
The use of Education from Neurosciences
}

\author{
David Fernando Alcívar Alcívar ${ }^{a}$ \\ Gina Mercedes Cuadros Solórzano ${ }^{b}$ \\ Elsa María Figueroa Sandoval c \\ María Yessenia Mantilla Cedeño ${ }^{d}$ \\ Marta Patricia Cuadros Solórzano ${ }^{\mathrm{e}}$
}

\section{Article history:}

Submitted: 09 November 2019

Revised: 18 December 2019

Accepted: 31 January 2020

\section{Keywords:}

cognitive learning processes; innovation;

neurosciences in education;

students;

teaching methods;

\begin{abstract}
The general objective of this research is the use of new technologies in education starting from neurosciences since a study of the student must be carried out to identify their abilities and apply new knowledge techniques and generate new learning. Each of the teachers nowadays should consider the use of ICT, as support in the classroom as it allows students to use this software's in the class that contains learning and then generate the same new knowledge that each one can evoke. Whenever necessary. The result that has been obtained is to identify software that contributes significantly to the teaching-learning processes in the different areas since by teaching the chairs with innovation, the interest of the students is aroused.
\end{abstract}

International research journal of engineering, IT \& scientific research (C) 2020.

This is an open access article under the CC BY-NC-ND license (https://creativecommons.org/licenses/by-nc-nd/4.0/).

\section{Corresponding author:}

David Fernando Alcívar Alcívar,

Foreign Languages \& Applied Linguistics

Shanghai International Studies University (SISU), China.

Email address: irjeis@sloap.org

${ }^{a}$ Pontificia Universidad Católica Del Ecuador, Sede Manabí, Portoviejo, Ecuador

b Pontificia Universidad Católica Del Ecuador, Sede Manabí, Portoviejo, Ecuador

c Pontificia Universidad Católica Del Ecuador, Sede Manabí, Portoviejo, Ecuador

d Pontificia Universidad Católica Del Ecuador, Sede Manabí, Portoviejo, Ecuador

e Pontificia Universidad Católica Del Ecuador, Sede Manabí, Portoviejo, Ecuador 


\section{Introduction}

Considering that the human brain plays an important role in the acquisition of new knowledge and the generation of new learning having a preponderant role at the time of storage and evocation as a cognitive process (López, 2000). The first teachings start from the early age when an individual is in the process of pregnancy begins to have feelings with their environment, when born to interact with their parents, this has relevant implications in health and learning processes (Fernández-Rio \& Méndez-Giménez, 2016).

The child has the power and ability to interact with the environment, collect, analyze and adapt the information according to their level, and gradually accumulating their abilities and skills in a way that reaches their understanding, it should be noted that this process is slow and progressive and that often requires the contribution of those around the individual such as the family, the school environment and society itself According to (Franco, 2019). In the educational units at present, s are very little used despite having the tools because teachers do not know the management of software (Meneses et al., 2020), so the contents that must be addressed during the school year are not developed or deepened, because these students are unaware of many factors that would enrich the new knowledge generated during class. In this way, constructivism considers learning as the result of the construction that the subject himself performs when interacting with (Saldarriaga, 2016).

There are several types of strategies when using, but for this, you must consider the material that is available to be able to execute the strategies correctly, and that all students can private actively solving correctly the exercises that the teacher poses during your hour. All the experience that people around the child have, such as parents, teachers, and others, has a positive influence from the moment the child observes the behavior of these people, and therefore, by imitating these actions, a great contribution is made to the development of skills and knowledge necessary to achieve full evolution as a social individual Ferreira (2016).

Other factors that cause difficulties when teaching are learning disorders that students may have, some of the most frequent are dyscalculia and TDH. Regarding dyscalculia It should be noted that this problem is not related to the child's degree of intelligence or the strategies or methodology applied by the teacher, this problem is related to the child's ability to interpret the numbers with the set of basic operations, usually leading to the confusion of numbers and signs making it difficult to perform small calculations (Breznitz, 2017). TDH is a neurobiological disorder and individuals reflect the inability to attend, movements and impulsivity when acting; this type of expression sometimes makes learning difficult, for this, it is necessary to draw up innovative strategies to achieve in the students with the presence of this disorder they manage to attend the classes that a teacher teaches (Carbajo, 2016).

\section{Materials and Methods}

In the educational process, the use of ICT is a tool that allows the acquisition of new knowledge, achieving effective learning that encourages research and encourages students to carry out more creative and truthful academic work. According to Cadavieco and Sevillano, the use of M-learning modifies both the form and the educational contents, which are new methodologies that leave aside the traditional ways of teaching scientific production on augmented reality, an analysis of the situation education from the perspective Scopus (Sevillano, 2016). The methodology of education must be constantly changing, so it is necessary that teachers and students apply TIC in the classroom, looking for students to adopt new ways of learning. It is of vital importance that teachers are trained in the use of TIC, they have tools of various kinds, which are used in the different subjects to be taught to make learning easier and more creative.

According to Claudia Islas Torres, in the age of knowledge, technology is associated with the level of study (Torres, 2017). According to the above, the level of study results in the search for new knowledge, also showing that it is consistent with global advances, that is, the use of technology will give students a better level of study, then the Institutional education should also focus on the constant use of ICT as learning tools. Manifiesta Escontrela, the ancient nature of learning underline as central qualities of abstraction and transfer, in them, that knowledge is applied with the use of the five senses that allow generalization (Escontrela, 2004). These are interesting ways of learning, which does not mean that the use of technological tools is neglected since the use of them will make the absorption and transfer of knowledge effective. Other authors Lucas et al. (2019), state the factors that influence school delay and its consequences on academic performance. 
Taking into consideration what Lilia de la Torre says, the characteristics of virtual learning, is the fact that the face-to-face act of the teacher and student is not mandatory, chasing the student to see it as something satisfactory and entertaining (Torre \& Domínguez, 2012). Currently, teachers become spectators and guide students, which allows the same student to be the protagonist of their learning.

\section{Cognitive processes}

Fuenmayor states that cognitive processes are necessary for the constructive and interpretive process of understanding since it is everyone's knowledge that reading implies the interaction between the information obtained and the information stored in the reader's brain, to obtain coherent information (Fuenmayor, 2008). The thinking according to the actors Mejía and Escobar is the ability to analyze, compare. Evaluate, judge, generate new ideas and help solve problems (Quintero \& Escobar, 2012).

Sandra Lizardo states that the cognitive process of comparison is promoted in students through the formulation of approaches and questions that point to the establishment of differences between certain aspects of the content worked in the classroom (V., 2006). Lorenzo argues that the basic processes are responsible for the coding of the text, translating a series of graphemes to the phonemes during the coding and autonomous identification of words (Lorenzo, 2001). Lorenzo states that viso-spatial processes are responsible for the visual procedure of the text, in both graphemes are a series of symbols with precise orientation and forms (Lorenzo, 2001).

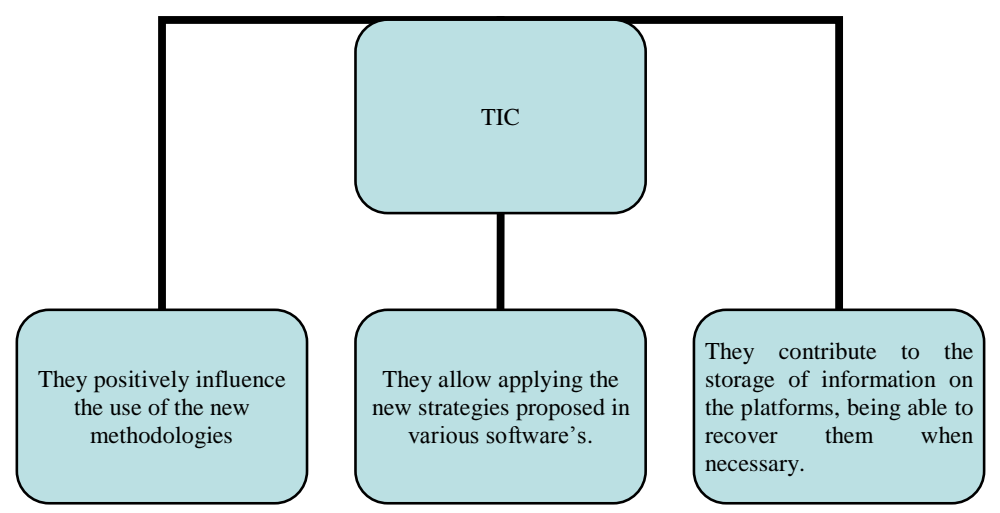

Figure 1. Concept and application

\section{Results and Discussions}

\section{Teaching methods learning}

They constitute the techniques and resources for the teaching process, it can be said that they are vehicles in an orderly and systems way, which aim to make the learning direction more efficient. The TIC can be implemented to improve the teaching-learning process seen by some authors (Mero et al., 2019). In the teaching-learning process, the contents become an end, which in some cases leads the student to memorization and the mechanism, since it fails to form creative and reflective learning, resulting in students with little desire to learn, with boredom due to repetitive work, which the teacher has. That is the importance of the use of teaching methods (Martín, 1998). Within the Teaching-Learning methods, we find several classifications, which are related to each other, depending on the purpose sought (Phillips, 2012). The teacher will have the facility to use the methods and strategies that he considers convenient, without forgetting that the purpose of his use is, to train new knowledge in the students, using the appropriate didactics (Alava \& Martinez, 2019; Macías et al., 2018).

Alcívar, D. F. A., Solórzano, G. M. C., Sandoval, E. M. F., Cedeño, M. Y. M., \& Solórzano, M. P. C. (2020). The use of education from neurosciences. International Research Journal of Engineering, IT \& Scientific Research, 6(2), 1-6. https://doi.org/10.21744/irjeis.v6n2.856 


\subsection{Methods as to their way of reasoning \\ Deductive method}

It is that by tradition they are used more in the teaching process, although it should not be forgotten that for the learning of cognitive strategies, or creation of concepts, they are the least adequate. Deductive reasoning can order what is already known and indicate new relationships as it goes from general to specific, but without becoming a source of new truths (Dávila, 2006).

\subsection{Inductive method}

It is an active method, which gives rise to scientific discovery. It is based on experience, on parathion, on facts. When the teacher uses this method, he must be careful not to give too many examples that are not too complicated or long, since the student needs to relate it to his experience, without forgetting that the deductive method cannot be excluded (Gabrielsson, 2011).

\subsection{The analog or comparative method}

It is to reason through analogies, it is about finding two situations or elements that meet similar characterize or similarities to each other, for which we will need a systems and rigorous work that implies the previous definition of properties and attributes possible to be compared, and thus be able to confront the stated properties of the object (Tonon, 2011). The use of this method in the educational field allows the student to discover new knowledge, developing his analysis and reflexive capacity.

The Learning Teaching process has given a great change, giving great importance to each of the roles that both the teacher and the student plays, so that the acquisition of knowledge, the development of skills and values, is associated with method that the teacher selects and uses, depending on the purpose set (Carlos \& Elena, 2016). Being this one more tool, which facilitates the teaching-learning process, providing the teacher with techniques and strategies, to reach the desired objective and helping the student to be the protagonist of the class, developing their skills and values.

\section{Conclusion}

It is important to know that the brain is unknown when trying to know all its functions, but it is relevant to knowhow through neurosciences students can be approached and thus facilitate the teaching-learning process. Neuroscience is an interdisciplinary science that has a significant relationship in the use of, as a tool in the process of generating new knowledge. Identify the importance of learning processes contribute greatly to the correct use of $s$ based on learning and memorization of knowledge, to be able to evoke them. Has given a significant contribution to the development, education, of the human being, since through its use new knowledge is generated, in a versatile way and sometimes easier and more fun.

\section{Conflict of interest statement}

The authors declared that they have no competing interests.

Statement of authorship

The authors have a responsibility for the conception and design of the study. The authors have approved the final article.

\section{Acknowledgments}

We are grateful to two anonymous reviewers for their valuable comments on the earlier version of this paper. 


\section{References}

Alava, E. E., \& Martinez, M. E. M. (2019). Impact of teaching-learning process for brain. International Journal of Health Sciences, 3(1), 33-40. https://doi.org/10.29332/ijhs.v3n1.304

Breznitz, S. (2017). Infantile dyscalculia Cognifit.

Carbajo, S. (2016). ADHD Disorder plunged deep misinformation.

Carlos, H.I., \& Elena, I.M. (2016). The method of teaching-learning of independent work in the class meeting: didac recommendations. Pedagogy Magazine, 37(101), 215-231.

Dávila Newman, G. (2006). Redalyc, 12, 180-205.

Fernández-Rio, J., \& Méndez-Giménez, A. (2016). Cooperative learning: Pedagogical model for Physical Education. Challenges New Trends in Physical Education, Sports and Recreation, (29), 201-206.

Ferreira, Y. (2016). The social cognitive learning of Albert Bandura and the psychogene theory of Jean Piaget. Chorus, Venezuela Recovered.

Franco, F. (2019). Piaget and his learning theory. The mind is wonderful.

Fuenmayor, G., \& Villasmil, Y. (2008). Perception, attention and memory as cognitive processes used for textual comprehension. Arts and humanities magazine UNICA , 9 (22), 187-202.

Fuentes-Garcia, A.-M., \& Heredia-Martinez, N. (2017). La competencia digital en la base de Scopus: un estudio de metaanálisis. Revista de Estudios y Experiencias en Educación, 16.

Gabrielsson, S. (2011). Un análisis cualitativo de los métodos deductivo, inductivo y aprender haciendo. Universitet LUNDS.

López, C.A. (2000). Brain, Learning and Research: Connections. In CA López, Brain, Learning and Research: Connections (p. 386).

Lorenzo, JR (2001). Basic cognitive processes connected. Primera parte: phonological la concience. redalyc, 8.

Lorenzo, R. (2001). *Basic ocessoscognitivosrelacionadosconlalectura.primeraparte: laconcienciafonologic. redalyc, $*$.

Lucas, M.; Moya, M.; \& Rodriguez, M. (2019). Factors that influence school delay and its consequences on academic performance. Journal of Advanced Research in Dynamical and Control Systems, 11(08)-Special Issue.

Macías, EIP, Cedeño, HAC, \& Chávez, GMR (2018). Importance of Improving Resilience in Teaching-Learning Process of Students with Disabilities. International Research Journal of Management, IT and Social Sciences , 5 (2), 120-128.

Martín, J.D. (1998). Teaching method. learning for teaching.

Mejía Quintero, E., \& Escobar Melo, H. (2012). Characterization of cognitive processes of memory, language and thought, in students with low and high academic performance *. REDALYC, 6.

Meneses, I., Moya, M., \& Rodriguez, M. (2020). Influence of Videogames on Student Behavior. International Journal Psychosocial Rehabilitation. 24(1).

Mero, E., Pazmiño, M., \& Rodriguez M. (2019). An Innovative Proposal For Teaching Learning: The Inverted Classroom. Journal of Advanced Research in Dynamical and Control Systems, 11(08)-Special Issue.

Phillips, J. J. (2012). Handbook of training evaluation and measurement methods. Routledge.

Ramón Escontrela Mao, L.S. (2004). The integration of ICT in education: Notes for a relevant pedagogical model.

Saldarriaga, P. (2016). The constructivist theory of Jean Piaget and its significance for contemporary Pedagogy. Scientific magazine Domain of Sciences.

Sevillano, J.F. (2016). Scientific production on augmented reality, an analysis of the economic situation from the SCOPUS perspective. Edme Media Education and, 2.

Tonon, G. (2011). The use of the comparative method in studies. (P. u. S, Ed.) KAIROS. R evistade T emas S ociales (27), 12 .

Torre, L., \& Domínguez, J. (2012). Las TIC en el proceso de enseñanza aprendizaje a través de los objetos de aprendizaje. Revista Cubana de Informática Médica, 4(1).

Torres, C.I. (2017). The involvement of the in education: Scope, limitations and prospective. Scielo, 5.

V., SL (2006). Cognitive processes and the pattern of verbal interaction in the university classroom. SCIELO.

Alcívar, D. F. A., Solórzano, G. M. C., Sandoval, E. M. F., Cedeño, M. Y. M., \& Solórzano, M. P. C. (2020). The use of education from neurosciences. International Research Journal of Engineering, IT \& Scientific Research, 6(2), 1-6. https://doi.org/10.21744/irjeis.v6n2.856 


\section{Biography of Authors}

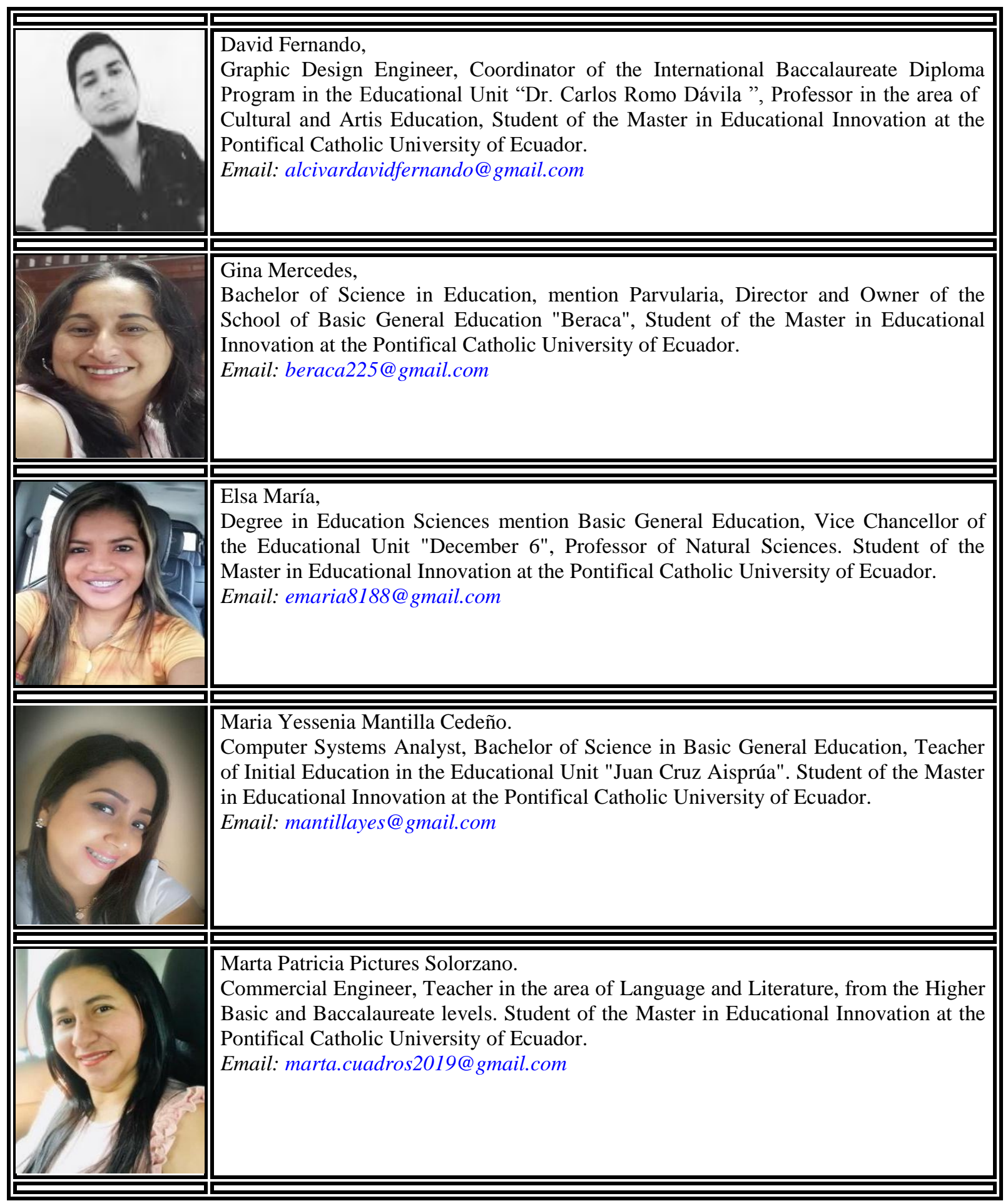

